ORIGINAL ARTICLE

\title{
Crisis management during anaesthesia: regurgitation, vomiting, and aspiration
}

\author{
M T Kluger, T Visvanathan, J A Myburgh, R N Westhorpe
}

Qual Saf Health Care 2005;14:e4 (http://www.qshc.com/cgi/content/full/14/3/e4). doi: 10.1136/qshc.2002.004259

See end of article for authors' affiliations

Correspondence to: Professor W B Runciman, President, Australian Patient Safety Foundation GPO Box 400, Adelaide, South Australia 5001, Australia; research@apsf. net.au

Accepted 10 January 2005
Background: Regurgitation, vomiting and aspiration may occur unexpectedly in association with anaesthesia. "Aspiration/regurgitation" was ranked fifth in a large collection of previously reported incidents that arose during general anaesthesia. These problems are encountered by all practising anaesthetists and require instant recognition and a rapid, appropriate response. However, the diagnosis may not be immediately apparent as the initial presentation may vary from laryngospasm, desaturation, bronchospasm or hypoventilation to cardiac arrest.

Objectives: To examine the role of a previously described core algorithm "COVER ABCD-A SWIFT $\mathrm{CHECK}^{\prime \prime}$, supplemented by a specific sub-algorithm for regurgitation, vomiting and aspiration, in the management of these complications occurring in association with anaesthesia.

Methods: The potential performance of this structured approach for each of the relevant incidents among the first 4000 reported to the Australian Incident Monitoring Study (AIMS) was compared with the actual management as reported by the anaesthetists involved.

Results: There were 183 relevant incidents of regurgitation, vomiting and aspiration among the first 4000 reports to the AIMS. Aspiration was documented in 96, was excluded in 69, and in 18 it could not be determined whether or not aspiration had occurred. It was considered that the correct use of an explicit algorithm would have led to earlier recognition and/or better management of the problem in 10\% of all cases of regurgitation and vomiting and in 19\% of those in which aspiration occurred.

Conclusion: Regurgitation and/or aspiration should always be considered immediately in any spontaneously breathing patient who suffers desaturation, laryngospasm, airway obstruction, bronchospasm, bradycardia, or cardiac arrest. Any patient in whom aspiration is suspected must be closely monitored in an appropriate perioperative facility, the acuity of which will depend on local staffing and workload. If clinical instability is likely to persist or if there are concerns by attending staff, the patient should be admitted to a high dependency unit or intensive care unit.
$\mathrm{R}$ egurgitation, vomiting and aspiration may occur quite unexpectedly in association with anaesthesia and may have serious sequelae. "Aspiration/regurgitation" was ranked fifth and comprised over 5\% of a large collection of incidents that arose during general anaesthesia. ${ }^{1}$ Aspiration has been reported to occur with a frequency of $0.7-4.7$ per 10000 anaesthetics. ${ }^{2}{ }^{3}$ There appears to be a higher rate of aspiration in children ( 10.2 per 10000 anaesthetics) than in adults. ${ }^{4}$ Of note, the reported incidence in obstetric patients undergoing general anaesthesia during or immediately after delivery was similar to that of the general population ( 5.3 per 10000 anaesthetics). ${ }^{5}$ The mortality following aspiration varies between 1 in 35000 and 1 in 72000 patients. ${ }^{26}$ While attention has usually focused on aspiration as the major consequence of regurgitation and vomiting, other sequelae such as laryngospasm, desaturation and bronchospasm are also important. These problems are encountered by all practising anaesthetists and present as emergencies requiring instant recognition and a rapid appropriate response. This paper will focus broadly on aspects of regurgitation and aspiration in anaesthesia as reported to AIMS, and examine the place of a structured approach in dealing with the management of these problems.

In 1993 a "core" crisis management algorithm, represented by the mnemonic COVER ABCD-A SWIFT CHECK (the AB precedes COVER for the non-intubated patient), was proposed as the basis of a systemic approach to any crisis during anaesthesia where it is not immediately obvious what should be done or where actions taken have failed to remedy the situation. ${ }^{7}$ This was validated against the first 2000 incidents reported to the original Australian Incident Monitoring Study (AIMS). AIMS is an ongoing study which involves the voluntary anonymous reporting of any unintended incident which reduced or could have reduced the safety margin for a patient. ${ }^{8}$

It was concluded that, if this algorithm had been correctly applied, a functional diagnosis would have been reached within 40-60 seconds in 99\% of applicable incidents, and that the learned sequence of actions recommended by the COVER portion would have led to appropriate steps being taken to handle the $60 \%$ of problems relevant to this portion of the algorithm. ${ }^{7}$ However, this study also showed that the $40 \%$ of problems represented by the remainder of the algorithm, ABCD-A SWIFT CHECK, were not always promptly diagnosed or appropriately managed. ${ }^{178}$ It was decided that it would be useful, for these remaining problems, to develop a set of sub-algorithms in an easy to use crisis management manual. ${ }^{9}$ This study reports on the place of the AB COVER CD-A SWIFT CHECK algorithm in the diagnosis and initial management of regurgitation, vomiting or aspiration, provides an outline of a specific crisis management algorithm for these problems during anaesthesia, and provides an indication of the potential value of using this structured approach.

\section{METHODS}

Of the first 4000 incidents reported to AIMS, those that made reference to regurgitation, vomiting or aspiration were extracted and analysed for relevance, presenting features, type of surgery, cause, management, and outcome. The AB 


\section{REGURGITATION/VOMITING}

\section{MANAGEMENT}

Inform the surgeon

Head down, lateral posture, if feasible

Apply cricoid pressure

Try to clear and suction the airway

Give $100 \%$ oxygen

Consider deepening anaesthesia $(1)^{*}$ to visualise and clear the pharynx/airway

Try gentle mask CPAP/IPPV with cricoid pressure (2)*

Ventilate the lungs with cricoid pressure

IF YOU CANNOT VENTILATE $\rightarrow$ page $14^{* *}$

Give suxamethonium and atropine.

Intubate with cricoid pressure, expedite surgery.

\section{ASPIRATION}

SIGNS (3)

Laryngospasm/airway obstruction

Bronchospasm/wheeze/crackles

Hypoventilation/dyspnoea/apnoea

Reduced compliance (ARDS)

Desaturation/bradycardia/arrest.

\section{FURTHER CARE}

Sedation, analgesia, IPPV via ETT

Suction airway, optimise $\mathrm{FIO}_{2}$ and PEEP

Bronchoscopy and lavage if necessary

Bronchodilators as necessary (4)

Chest $X$ ray. If normal, and

If saturation is adequate, extubate (5)

If stable after 2 hours in recovery, send to the ward and arrange for

follow up (5)

If unstable or saturation is inadequate (5)

Maintain intubation and IPPV

Admit to a high dependency area (6)

Explain what happened to relations/friends

Repeat chest $X$ ray and blood gases

Consider PEEP, bronchodilators, inotropes

Culture sputum

Antibiotics; not routine

Consider other causes (7)

Reassess daily (8).

Explain what happened to the patient

Arrange follow up as necessary.

The sub-algorithm forms a facing page of the

Crisis Management Manual ${ }^{12}$.

* Numbers in brackets refer to Notes in the right hand panel.

** Page reference refers to the Crisis Management Manual ${ }^{12}$.

\section{NOTES:}

It was judged that the correct use of the algorithm would have led to earlier recognition of the problem and/or better management in 19\% of the 96 incidents of aspiration reported to AIMS.

(1) An alternative is to allow the patient to recover consciousness and to start again. Deepening anaesthesia may be necessary to properly visualise and clear the pharynx/airway without precipitating laryngospasm and/or further aspiration or vomiting.

(2) An alternative, if the patient's condition allows, and the appropriate equipment and assistance is at hand, is to proceed immediately with intubation.

(3) Diagnosis of regurgitation, vomiting or aspiration was clinically obvious in $70 \%$ of cases. However $15 \%$ of cases of aspiration presented as desaturation, $6 \%$ as laryngospasm, $3 \%$ as airway obstruction, $2 \%$ as bronchospasm, $1 \%$ occurred with difficult intubation, $1 \%$ presented with hypoventilation, $0.5 \%$ as pulmonary oedema and $0.5 \%$ as cardiac arrest.

(4) Salbutamol: $0.5 \% 1 \mathrm{ml}(5 \mathrm{mg})$ by mask nebuliser 4 hourly.

(5) "Stable": saturation 95\% with $\mathrm{FIO}_{2}<0.5$, heart rate $<100$, respiratory rate $<20 /$ minute (adults), no bronchospasm, apyrexial.

(6) Major morbidity ensued in $50 \%$ of all cases of aspiration and death ensued in $4 \%$.

(7) Bronchospasm, pulmonary oedema, ARDS, pulmonary embolism and other causes of ET tube obstruction may present a similar respiratory picture as aspiration.

(8) Steroids and antibiotics should not be used early or routinely.

These notes comprise a reverse side of a page of the Crisis Management Manual12.

Figure 1 Regurgitation/vomiting.

COVER CD-A SWIFT CHECK algorithm, as presented elsewhere in this series of articles, ${ }^{9}$ was applied to each relevant report to determine the stages at which the problem might have been diagnosed and to confirm that activating the COVER portion would have led to appropriate initial steps being taken. As regurgitation, vomiting and aspiration are not dealt with by this algorithm, a specific sub-algorithm was developed for these problems (fig 1) and its putative effectiveness was tested against the reports. The potential value of this structured approach-that is, the application of AB COVER CD-A SWIFT CHECK to the diagnosis and initial management of this problem and the application of the subalgorithm for regurgitation, vomiting and aspiration-was assessed in the light of the AIMS reports by comparing its potential effectiveness for each incident with that of the actual management, as recorded in each report.

\section{RESULTS}

Among the first 4000 AIMS reports there were 198 cases of regurgitation, vomiting or aspiration. Fifteen of these were excluded from further consideration either because other diagnoses were evident after review of the reports or because it was considered that these problems had not played a significant role in the incident. Of the remaining 183 incidents, 96 had evidence of pulmonary aspiration and 69 were documented not to have been associated with pulmonary aspiration. In 18 it was not clear from the report whether or not aspiration had occurred.

Regurgitation, vomiting or aspiration was clinically obvious in 128 cases $(70 \%)$. A further 28 cases (15\%) presented as desaturation (24 in the aspiration group), 11 cases $(6 \%)$ as laryngospasm (eight in the aspiration group), five cases $(3 \%)$ as airway obstruction (four in the aspiration 
group), and four as bronchospasm (all in the aspiration group). A further eight cases of bronchospasm with aspiration occurred in which bronchospasm was not the presenting feature. Of the remaining patients who aspirated, two did so during difficult intubations, two presented as hypoventilation, one presented as bradycardia, and one as a cardiac arrest.

Of the 96 reports in which regurgitation or vomiting caused aspiration, $54(56 \%)$ were in elective and 42 (44\%) in emergency cases. The interventions undertaken in these patients are shown in table 1 .

Major morbidity ensued in 48 cases $(50 \%)$, minor morbidity in 41 cases (43\%), and death in four cases $(4 \%)$. In one case no outcome was documented and in two it was considered that there were no adverse sequelae. Admission to an intensive care unit was documented in 28 cases. Of the 69 reports in which regurgitation and vomiting did not cause aspiration, $19(28 \%)$ were in elective and $47(68 \%)$ were in emergency cases. In three cases the status of the patient was unknown. Forty eight cases (70\%) suffered no adverse effects and the remaining 21 suffered minor morbidity (desaturation in 10 cases, laryngospasm in three, and airway obstruction in one). No major morbidity was documented in the 18 incidents in which it was not clear from the reports whether aspiration had occurred or not.

When the AB COVER CD-A SWIFT CHECK algorithm was applied to each report, it was considered that the majority of cases would have been detected at the A (Airway) or B (Breathing) stages preceding COVER, if not at the SCAN level ( $70 \%$ of cases were clinically obvious), then at the CHECK level. The terms SCAN and CHECK are discussed elsewhere in this set of articles. ${ }^{9}$ However, 28 cases (15\%) presented as desaturation and hence would have been detected at the C2 (Colour) stage of COVER. It was considered that the nature of the problem would always have been detected at the A stage of the $\mathrm{AB}$ preceding COVER at the CHECK level, but that the few specific remediable causes would require application of the sub-algorithm in order to be identified. The actions recommended by the COVER portion ( $100 \%$ oxygen, turning off the vaporiser and, if necessary, removing the patient from the anaesthetic machine, filter and circuit) were all considered reasonable immediate steps. It was also considered that carrying out the recommendations of the specific subalgorithm outlined in fig 1 would have constituted an acceptable course of action.

When the potential effectiveness of the structured approach represented by the AB COVER CD-A SWIFT CHECK algorithm and the special sub-algorithm for regurgitation, vomiting and aspiration (fig 1) was compared with that of the actual management as documented in each of the 183 incident reports, it was considered that, properly applied, the structured approach recommended would have led to a quicker and/or better resolution of the problem in 18 cases

Table 1 Documented management of patients with aspiration $(n=96)$

\begin{tabular}{llr}
\hline Management* $^{*}$ & $\mathbf{n}$ & $\%$ \\
\hline Intubation & 70 & 73 \\
Suction & 60 & 62 \\
Antibiotics & 9 & 9 \\
Bronchodilators & 9 & 9 \\
Bronchoscopy & 6 & 6 \\
Steroids & 5 & 5 \\
Inotropes & 2 & 2 \\
CPAP & 1 & 1 \\
\hline
\end{tabular}

CPAP, continuous positive airway pressure. *More than one management approach was used in some patients.
( $10 \%$ overall and $19 \%$ of the aspiration group). These were all cases of aspiration in which problems arose because of inadequate intervention-for example, airway not secured (eight cases), not placed in lateral or "head down" position (five cases), no cricoid pressure (four cases), airway not suctioned (two cases) - or because an inappropriate action was taken-for example, not admitted to a high dependency area after proven aspiration; intravenous dexamethasone, resulting in convulsions. In general, the incidents were managed well as it was considered that the algorithm would have performed no better than the anaesthetist in 167 cases $(91 \%)$.

\section{DISCUSSION}

Regurgitation, vomiting and aspiration are quite commonly perceived by anaesthetists to be significant problems as they comprised $183(5 \%)$ of the first 4000 incidents reported to AIMS. Also, these problems comprise a significant proportion of the major complications and deaths attributable to anaesthesia. The reports analysed here form part of a larger study of this problem using the AIMS collection of incidents. $^{10}$

The diagnosis was clinically obvious in $70 \%$ of the cases reported and presented as laryngospasm or airway obstruction in a further $9 \%$. However, $15 \%$ presented as desaturation, $3 \%$ as bronchospasm, and one case as cardiac arrest. Thus, although $80 \%$ of cases of regurgitation, vomiting or aspiration should be diagnosed at the A stage of $\mathrm{AB}$ (preceding COVER in the spontaneously breathing patient), it is important to recognise that $20 \%$ of patients present in different ways. These problems must immediately be considered in any spontaneously breathing patient who presents with unexplained desaturation, laryngospasm, airway obstruction, hypoventilation, bronchospasm, pulmonary oedema, or cardiac arrest.

In $81 \%$ of cases in the aspiration group it was considered that the anaesthetist managed the problem quite adequately. However, in 19\% it was considered that the problem would have been better managed had a structured algorithm been followed, and it was concluded that the AB COVER CD-A SWIFT CHECK algorithm is still worth following even when the diagnosis seems obvious, as in some cases an underlying and ongoing cause of the problem was revealed-for example, an unintended excessive concentration of irritant vapour causing coughing and vomiting; or inadvertent administration of a muscle relaxant.

Review of the AIMS reports also supported the use of each of the steps in the specific sub-algorithm (fig 1). Although the surgeon may oppose placing the patient in a head down and lateral position, this should be done whenever possible. There were several cases of aspiration with major sequelae in patients who were not placed on their sides (for example, orthopaedic cases), who were left in the lithotomy position or on their backs (for example, during urological or gynaecological surgery), or who were not placed head down (for example, with major plastic surgery to the face). It may be necessary for the anaesthetist to point out to the surgeon that aspiration is a potentially life threatening complication. ${ }^{6}{ }^{10}$

The airway should be secured as soon as possible with placement of an endotracheal tube using rapid sequence induction with cricoid pressure. There were several cases in which the airway was not secured and in which the patient went on to regurgitate again, sometimes with pulmonary aspiration. Once the airway has been secured, thorough suctioning of the trachea and accessible bronchi should take place. Again, this was not carried out in some patients who were later shown to have considerable soiling of their major airways. Rigid bronchoscopy should be considered if there is thought to be particulate matter in the major airways. ${ }^{11}$ 


\section{Key messages}

- Of the 183 relevant incidents among the first 4000 AIMS reports, 96 showed evidence of pulmonary aspiration. In 128 cases (70\%) regurgitation, vomiting or aspiration was clinically obvious.

- As $20 \%$ of such cases present in different ways, these complications must be considered in any spontaneously breathing patient presenting with unexplained desaturation, laryngospasm, airway obstruction, hypoventilation, bronchospasm, pulmonary oedema, or cardiac arrest.

- $56 \%$ of the 96 cases of aspiration were elective procedures.

- In 48 cases of aspiration (50\%) major morbidity resulted, with death in four patients (4\%).

- Although the majority (81\%) of the reported aspiration cases were managed satisfactorily, it was considered that a structured approach would have resulted in better management in $19 \%$ of the cases.

- Surgical opposition to placing the patient rapidly in the head down, lateral position should be countered with the fact that aspiration is a potentially life threatening situation.

- Consider rigid bronchoscopy for suspected particulate matter in the airways.

- Twenty eight cases required admission to an intensive care unit.

- Criteria for monitored discharge of patients who have aspirated to a general ward are: clinical stability, $\mathrm{SpO}_{2}$ $>95 \%$ on $\mathrm{FlO}_{2}<50 \%$, heart rate $<100$ beats $/ \mathrm{min}$, respiratory rate $<20 / \mathrm{min}$, temperature normal, minimal bronchodilation needed.

Finally, careful evaluation and monitoring of the patient in the postoperative period is essential. For most patients, observation in the recovery ward for at least 2 hours is essential, ${ }^{6}$ although this will depend on staff levels and workload. A chest radiograph should always be obtained if aspiration is suspected. Adequate doses of nebulised bronchodilators should be used if there is bronchospasm, and continuous positive airway pressure or positive end-expiratory pressure should be used with artificial ventilation if there is evidence of reduced compliance or poor gas exchange. There is no evidence that intravenous steroids have a place in treatment, and one patient convulsed after the injection of a large dose of intravenous dexamethasone. Antibiotics should not be used prophylactically but should be used if and when a specific organism is identified. ${ }^{11}$ If the patient is stable, the saturation is greater than $95 \%$ with an inspired oxygen concentration of less than $50 \%$, the heart rate is less than 100 beats/min (in adults), the respiratory rate is less than 20/min (in adults), and the patient is apyrexial and requires minimal bronchodilators, then discharge to a general ward with appropriate monitoring is acceptable. If these criteria are not satisfied at 2 hours, the patient should be admitted to an intensive care or high dependency unit. ${ }^{6}$

A further study of the AIMS database looked at aspiration in a larger group of 133 cases of aspiration reported to AIMS. ${ }^{10}$ In this study aspiration occurred twice as often in elective patients than in emergency patients, with $56 \%$ of incidents occurring during the induction phase of anaesthesia. The majority of patients had recognised risk factors for aspiration. The most important contributing factor for the generation of the incident was inadequate anaesthesia, while the most important alleviating factors were prior experience and skilled assistance. The application of a simple management plan to prevent aspiration was considered to have the potential to prevent over two thirds of the reported cases.

In summary, regurgitation, vomiting and aspiration may occur unexpectedly in association with general anaesthesia and constitute an emergency that requires immediate appropriate action, as the consequences may be serious for the patient. Regurgitation and/or aspiration should always be considered immediately in any spontaneously breathing patient who suffers desaturation, laryngospasm, airway obstruction, bronchospasm, bradycardia, or cardiac arrest. The structured approach outlined in fig 1 should be carried out immediately and the AB COVER CD algorithm applied to exclude extraneous precipitating causes. Any patient in whom aspiration is suspected must be monitored in the recovery ward for at least 2 hours. At this stage, if the patient is unstable or there is cardiorespiratory compromise, he or she should be admitted to an intensive care or high dependency unit until the problem has resolved.

Finally, it is important that a full explanation of what happened be given to the patient, that the event and the results of any tests should be documented in the anaesthetic record and, if appropriate, that the patient be given a letter to warn future anaesthetists. If necessary, a permanent warning bracelet should be worn by the patient. If a particular precipitating event was significant or a particular action was useful in resolving the crisis, this should be clearly explained and documented.

\section{ACKNOWLEDGEMENTS}

The authors would like to thank all the anaesthetists in Australia and New Zealand who contributed to the 4000 incident reports upon which this and the other 24 papers in the Crisis Management Series are based. The coordinators of the project also thank Liz Brown for preparing the draft of the original Crisis Management Manual; Loretta Smyth for typing; Monika Bullock RN for earlier coding and classifying of data; Dr Charles Bradfield for the electronic version of the algorithms; Dr Klee Benveniste for literature research; and Drs Klee Benveniste, Michal Kluger, John Williamson and Andrew Paix for editing and checking manuscripts.

\section{Authors' affiliations}

M T Kluger, Senior Staff Specialist, Department of Anaesthesiology and Perioperative Medicine, North Shore Hospital, Auckland, New Zealand T Visvanathan, Staff Specialist, Department of Anaesthesia, The Queen Elizabeth Hospital, Woodville, South Australia, Australia

J A Myburgh, Associate Professor, University of New South Wales; Director of Research, Department of Intensive Care Medicine, The St George Hospital, Sydney, New South Wales, Australia

R N Westhorpe, Deputy Director, Department of Paediatric Anaesthesia and Pain Management, Royal Children's Hospital, Parkville, Victoria, Australia

This study was coordinated by The Australian Patient Safety Foundation, GPO Box 400, Adelaide, South Australia 5001, Australia.

\section{REFERENCES}

1 Webb RK, van der Walt JH, Runciman WB, et al. Which monitor? An analysis of 2000 incident reports. Anaesth Intensive Care 1993;21:529-42.

2 Mellin-Olsen J, Fasting S, Gisvold SE. Routine preoperative gastric emptying is seldom indicated: a study of 85,594 anaesthetics with special focus on aspiration pneumonia. Acta Anaesthesiol Scand 1996;40:1184-8.

3 Olsson GL, Hallen B, Hambreus-Jonzon K. Aspiration during anaesthesia: a computer-aided study of 185,358 anaesthetics. Acta Anaesthesiol Scand 1986;30:84-92.

4 Borland LM, Sereika SM, Woelfel SK, et al. Pulmonary aspiration in paediatric patients during general anaesthesia: incidence and outcome. J Clin Anaesth 1998; 10:95-102

5 Ezri T, Szmuk P, Stein A, et al. Peripartum general anaesthesia without tracheal intubation: incidence of aspiration pneumonia. Anaesthesia 2000;55:421-6.

6 Warner MA, Warner ME, Weber JG. Clinical significance of pulmonary aspiration during the perioperative period. Anesthesiology 1993;78:56-62. 
7 Runciman WB, Webb RK, Klepper ID, et al. Crisis management: validation of an algorithm by analysis of 2000 incident reports. Anaesth Intensive Care 1993;21:579-92.

8 Webb RK, Currie M, Morgan CA, et al. The Australian Incident Monitoring Study: an analysis of 2000 incident reports. Anaesth Intensive Care 1993:21:520-8

9 Runciman WB, Kluger MT, Morris RW, et al. Crisis management during anaesthesia: the development of an anaesthetic crisis management manual. Qual Saf Health Care 2005; 14:e1.
10 Kluger MT Short TG. Aspiration during anaesthesia: a review of 133 cases from the Australian Anaesthetic Monitoring Study (AIMS). Anaesthesia 1999;54:19-26.

11 Cooper DJ. Aspiration syndromes. In: Oh TE, ed. Intensive care manual. 4th ed. London: Butterworths, 1997:319-25.

12 Australian Patient Safety Foundation. Crisis Management Manual: COVER $A B C D$ A SWIFT CHECK. Adelaide: Australian Patient Safety Foundation, 1996, 74 pp. Available at http://www.apsf.net.au/anaesthesia.htm (accessed 6 September 2004). 